\title{
Pulmonary haemodynamics in awake rats following treatment with endotracheal pancreatic elastase
}

\author{
S. Sato, S. Kato, Y. Arisaka, H. Takahashi, H. Tomoike
}

Pulmonary haemodynamics in awake rats following treatment with endotracheal pancreatic elastase. S. Sato, S. Kato, Y. Arisaka, H. Takahashi, H. Tomoike. CERS Journals Ltd 1994.

ABSTRACT: The purpose of this paper was to study pulmonary haemodynamics in an elastase-induced emphysema model in awake rats (Group-EL, $n=9$ ) in comparison with saline-treated controls (Group-C, $n=12$ ).

Four weeks before haemodynamic study, porcine pancreatic elastase and normal saline were intratracheally instilled in Group-EL and Group-C, respectively. Indwelling pulmonary artery and abdominal aortic catheters were positioned two days before the haemodynamic study.

Breathing room air, mean pulmonary artery pressure (Ppa) tended to be higher in Group-EL than in Group-C, although the difference was not statistically significant. Systemic pressure, total systemic vascular resistance and cardiac index did not differ between groups. When exposed to $10 \% \mathrm{O}_{2}$, Ppa and pulmonary vascular resistance (PVR) of both groups rose significantly. The increase of Ppa, (but not PVR) in Group-EL during hypoxia was significantly higher than that in Group-C. The magnitude of hypoxic pulmonary vasoconstriction (HPV) tended to be larger in Group-EL than in Group-C. Right ventricles of Group-EL were more hypertrophic than those of Group-C, suggesting a period of higher pulmonary artery pressure than for Group-C.

The present results imply that the pressor response of pulmonary vasculature to acute alveolar hypoxia is possibly enhanced in awake rats upon examination four weeks after elastase treatment.

Eur Respir J., 1994, 7, 1294-1299.

The First Department of Internal Medicine, Yamagata University School of Medicine, Yamagata 990-23, Japan.

Correspondence: S. Sato

The First Department of Internal Medicine Yamagata University School of Medicine Yamagata 990-23

Japan

Keywords: Hypoxic pulmonary vasoconstriction

porcine pancreatic elastase

pulmonary emphysema

pulmonary haemodynamics

Received: March 151993

Accepted after revision January 151994
Pulmonary emphysema induced by intratracheal elastase has been widely-used as a disease model resembling human panacinar emphysema in many aspects [1-3]. In this model, capillary segments are disconnected and folded, and diffuse loss of capillaries occurs [4]. Changes in vascular smooth muscle [5], or contractile interstitial cells [6], which may regulate hypoxic pulmonary vasoconstriction, are also suggested. Radial stress applied to the extra-alveolar vessels within the lung parenchyma should be weakened, since elastic recoil pressure surrounding the vessels is lowered [7, 8]. These findings indicate that in this animal model, pulmonary haemodynamics may be altered not only during air breathing but also during alveolar hypoxia.

However, previous studies on this model have focused mainly on the morphological and biochemical aspects and ventilatory mechanics. Very little is known about the haemodynamic features of this model. The purposes of the present study were to obtain the pulmonary haemodynamic data of the frequently-used disease model during air breathing and to evaluate the haemodynamic response to acute alveolar hypoxia. An experiment on awake rats was chosen, to eliminate the effects of anaesthesia on pulmonary circulation [9]. Haemodynamic parameters were measured via indwelling pulmonary artery and abdominal aortic catheters.

\section{Method}

\section{Design of the study}

Male Wistar rats (postnatal 9 weeks) were anaesthetized with intraperitoneal injections of pentobarbital sodium (Somnopentyl, Pitman-Moore, NJ, USA), $5 \mathrm{mg} \cdot 100 \mathrm{~g}^{-1}$ BW. To the emphysema group (Group-EL), a single endotracheal instillation of porcine pancreatic elastase (US Biochemical Co., Cleveland, USA) was administered ( $80 \mathrm{U}$ in $0.2 \mathrm{ml}$ saline $\cdot 100 \mathrm{~g}^{-1} \mathrm{BW}$ ) [10]. Pancreatic elastase was dissolved in saline immediately before use. To the control group (Group-C), $0.2 \mathrm{ml}$ of saline. $100 \mathrm{~g}^{-1}$ BW was instilled. Four weeks after instillation, the haemodynamic and the histological studies were performed.

The lungs of 12 rats ( $n=6$ for each group) were fixed intratracheally at a pressure of $20 \mathrm{cmH}_{2} \mathrm{O}(14.7 \mathrm{mmHg})$ with $2.5 \%$ glutaraldehyde in $0.1 \mathrm{M}$ cacodylate buffer $\mathrm{pH}$ 
7.4. The speed of infusion of the fixative was high, 120 $\mathrm{ml} \cdot \mathrm{min}^{-1}$ at $20 \mathrm{cmH}_{2} \mathrm{O}(14.7 \mathrm{mmHg})$ [11]. Fifteen minutes later, the trachea was ligated and the whole lung was submerged in the same fixative. Standard methods were applied to produce haematoxylin-eosin-stained and elastic/Masson-stained tissues of the lung for histological examination. Measurements of external diameter (ED) and medial thickness (MT) of small muscular arteries displaying internal and external elastic laminae were performed with an ocular micrometer. From 12 slices of each group, sections of pulmonary arteries cut in a plane perpendicular to the long axis of each vessel were selected for morphometry. Mean values of minimal and maximal ED and of minimal and maximal MT were measured. Percentage MT was calculated as $100 \times 2 \times$ MT/ED [12]. All measured arteries larger than capillaries and less than $200 \mu \mathrm{m}$ were divided into three classes by size: $<50,50-100$ and 100-150 $\mu \mathrm{m}$.

\section{Catheter implantation}

Following induction of anaesthesia with intraperitoneal sodium pentobarbital $\left(5 \mathrm{mg} \cdot 100 \mathrm{~g}^{-1} \mathrm{BW}\right)$, the pulmonary artery was catheterized and the catheter maintained in situ by the modified technique of RABINOVITCH et al. [13]. A small incision was made in the neck, and the right jugular vein was isolated. With pressure monitored by an oscilloscope, a Silastic catheter (0.012 in internal diameter (ID); 0.025 in ED) filled with heparinized saline was advanced into the right ventricle through an introducer, whilst the Silastic catheter was manipulated into the pulmonary artery. The catheter connected to another thickwalled Silastic tube (0.025 in ID; 0.047 in ED) was fixed to the jugular vein and exteriorized at the back of the neck subcutaneously. The catheter was reattached to the transducer for final check and pressure recording and then closed with a blunt wire plug. The pressure transducers were zeroed at the mid-point of the thoracic cage in the supine position.

The abdominal aorta was cannulated by the modified method of WeEKS and Jones [14]. A mid-line incision was made, and the abdominal aorta was exposed just above the iliac bifurcation. A polyethylene catheter (PE10 fused to PE-50) fill heparinized saline was inserted into the aorta, and threaded subcutaneously along the back of the animal to the base of skull, where it was brought to the exterior. The catheters were flushed and filled with heparinized saline $\left(1,000 \mathrm{U} \cdot \mathrm{ml}^{-1}\right)$ and closed with blunt wire plugs. The next day, the catheters were flushed and filled with the concentrated heparin $(10,000$ $\left.\mathrm{U} \cdot \mathrm{ml}^{-1}\right)$.

\section{Haemodynamic measurements}

The haemodynamic study was performed in a clear Lucite chamber of $1 l$ capacity, in a similar method to that described by FRIED et al. [15]. Pulmonary artery and systemic artery catheters were connected to pressure transducers (Nihonkohden TP-101T Tokyo, Japan); pulmonary artery (Ppa) and systemic artery (Psa) pressures were recorded with a carrier amplifier and a recorder. The pressure transducers were zeroed at the mid-point of the thoracic cage in resting prone position. Mean of the mean Ppa and Psa for $30 \mathrm{~s}$ were used for the data presentation and resistance calculation.

A value of $3.8 \mathrm{mmHg}$ was assumed for mean capillary wedge pressure (Pcw) for both groups, a value which we have obtained in many saline- and elastase-treated rats. Mean Pcw of Group-EL was exactly the same as that of Group-C (unpublished data from our laboratory). Pulmonary vascular resistance (PVR) was calculated by dividing (Ppa-Pcw) by the cardiac output. Total systemic vascular resistance (SVR) was calculated by dividing Psa by cardiac output.

Blood samples were drawn into heparinized capillaries from the pulmonary artery and aorta $(0.2 \mathrm{ml}$ each) for measurement of mixed venous and systemic arterial $\mathrm{O}_{2}$ saturations $\left(\mathrm{S}_{\overline{\mathrm{v}}} \mathrm{O}_{2}, \mathrm{SaO}_{2}\right)$. The aortic blood $(0.1 \mathrm{ml})$ was also analysed for blood gases (arterial oxygen tension $\left(\mathrm{PaO}_{2}\right)$, arterial carbon dioxide tension $\left(\mathrm{PaCO}_{2}\right)$ and $\mathrm{pH})$. Oxygen saturation was measured by an IL-282 CO-Oximeter, and blood gas by an IL-813 blood gas analyser (Instrumentation Laboratories, Lexington, MA, USA).

Oxygen consumption $\left(\dot{\mathrm{V}}_{2}\right)$ was measured by circulating air or $10 \% \mathrm{O}_{2}$ through a $\mathrm{CO}_{2}$ absorber and desiccant and then pumping it through the chamber. The $\mathrm{O}_{2}$ consumed was replaced from a Krogh spirometer filled with $100 \% \mathrm{O}_{2}$ saturated with water vapour. The movement of the spirometer was recorded with a linear displacement transducer and the recorder described above. The system was run, refilling the spirometer with $100 \%$ $\mathrm{O}_{2}$ until stable linear utilization of $\mathrm{O}_{2}$ and thermal equilibration were achieved (about $7 \mathrm{~min}$ ). Oxygen consumption for $5 \mathrm{~min}$, while. blood was being sampled, was then determined, and $\dot{\mathrm{V}}_{2}$ was calculated, correcting the volume to standard temperature and presure, dry (STPD)[16].

Cardiac output was calculated using the following formula and indexed per $\mathrm{kg}$ body weight:

$$
\mathrm{CO}=\dot{\mathrm{V}}_{2} / 1.39 \times \mathrm{Hb} \times\left(\mathrm{SaO}_{2}-\mathrm{S}_{\overline{\mathrm{V}}} \mathrm{O}_{2}\right)
$$

where $\mathrm{Hb}$ is haemoglobin concentration.

\section{Experimental sequence}

Two days after surgery, animals were placed in the Lucite chamber and the chamber was ventilated with air at $5 l \cdot \mathrm{min}^{-1}$ for the first $5 \mathrm{~min}$, and then at $2 l \cdot \mathrm{min}^{-1}$. A $15 \mathrm{~min}$ acclimatization period was followed by aortic blood gas analysis in room air and the chamber was then closed. After $7 \mathrm{~min}$ of the thermal equilibration, measurements of oxygen consumption and haemodynamics were carried out and mixed venous and aortic blood samples were drawn. The air was then switched to $10 \% \mathrm{O}_{2}$ gas, and the chamber was ventilated at 5 $l \cdot \mathrm{min}^{-1}$ for the first $5 \mathrm{~min}$, and then at $2 l \cdot \mathrm{min}^{-1}$. Twenty two minutes were allowed to reach new hypoxic steady 
state. Measurements of $\dot{\mathrm{V}}_{2}$ and haemodynamics were again carried out. $\mathrm{S}_{\bar{v}}{ }_{2}$ and $\mathrm{SaO}_{2}$, and haemoglobin concentration were measured. Then, aortic blood gas analysis was performed. At the end of each experiment, the animal was anaesthetized with sodium pentobarbital and the position of the pulmonary artery catheter tip was confirmed to be in the pulmonary artery. Then, the heart was removed and placed in a $10 \%$ formalin. Seventy two hours later, the atria and the major blood vessels surrounding the heart were cut off, and the weights of right ventricle $(\mathrm{RV})$ and of left ventricle plus septum $(\mathrm{LV}+\mathrm{S})$ were obtained. Then, $\mathrm{RV} /(\mathrm{LV}+\mathrm{S})$ was calculated [17].

\section{Haemodynamic study three weeks after instillation}

Both in control and elastase-treated rats, which were not the same rats as those studied at four weeks, Ppa and Psa were measured during air breathing three weeks

Table 1. - Body weight, blood haemoglobin and right ventricular hypertrophy for two groups of rats

\begin{tabular}{lcc}
\hline & $\begin{array}{c}\text { Group-C } \\
(\mathrm{n}=12)\end{array}$ & $\begin{array}{c}\text { Group-EL } \\
(\mathrm{n}=9)\end{array}$ \\
\hline Initial weight $\mathrm{g}$ & $199 \pm 6$ & $187 \pm 4$ \\
Final weight $\mathrm{g}$ & $267 \pm 5$ & $272 \pm 7$ \\
$\mathrm{Hb} \mathrm{g} \cdot \mathrm{dl}^{-1}$ & $12.9 \pm 0.7$ & $12.9 \pm 1.3$ \\
$\mathrm{RV} /(\mathrm{LV}+\mathrm{S})$ & $0.231 \pm 0.007^{\dagger}$ & $0.273 \pm 0.010^{\# \#}$ \\
\hline
\end{tabular}

Data are presented as mean \pm SEM. Initial weight: body weight at tracheal instillation; Final weight: body weight at cannulation; $\mathrm{Hb}$ : blood haemoglobin concentration at the first cardiac output measurement; RV: weight of right ventricle; LV: weight of left ventricle; $S$ : weight of septum; Group-C: saline-treated group; Group-EL: elastase-treated group. \#\#: $\mathrm{p}<0.01$ vs Group-C; +: $\mathrm{n}=9$. after tracheal instillation. The values were compared with those obtained four weeks after instillation.

Data are presented as mean and SEM. Analysis of variance (ANOVA) was used to test significance of differences between groups, and Student's paired t-test for intra-individual differences. Differences were considered significant at $\mathrm{p}<0.05$.

\section{Results}

Both groups gained body weight similarly. Loss of blood due to surgery as assessed by haemoglobin concentration was also similar for both groups (table 1). Heart and respiratory rates of the two groups were not different (table 2).

The lung tissue for the elastase-treated group was characterized by diffuse and extensive dilatation and disruption of alveoli (fig. 1). There was a significant increase in percentage medial thickness of small pulmonary arteries in Group-EL (table 3).

\section{Haemodynamics during normoxia}

During normoxia, systemic artery pressure, total systemic artery resistance, cardiac index, and arterial and mixed venous blood gas data did not differ between the groups. Pulmonary artery pressure tended to be higher in Group-EL, but the difference was not statistically significant (table 2).

\section{Ppa and PVR responses to acute hypoxia}

Breathing $10 \% \mathrm{O}_{2}$ significantly lowered Psa in Group$\mathrm{C}(\mathrm{p}<0.01)$ and Group-EL $(\mathrm{p}<0.05)$. SVR decreased in

Table 2. - Respiratory, haemodynamic and arterial and mixed venous blood gas data during normoxia and hypoxia

\begin{tabular}{|c|c|c|c|c|}
\hline & \multicolumn{2}{|c|}{ Group-C $(n=12)$} & \multicolumn{2}{|c|}{ Group-EL (n=9) } \\
\hline & Air & $10 \% \mathrm{O}_{2}$ & Air & $10 \% \mathrm{O}_{2}$ \\
\hline HR beats $\cdot \mathrm{min}^{-1}$ & $424 \pm 11$ & $468 \pm 12 *$ & $343 \pm 38$ & $426 \pm 41 * *$ \\
\hline $\mathrm{RR}$ breaths $\cdot \mathrm{min}^{-1}$ & $95 \pm 7$ & $160 \pm 6^{* *}$ & $111 \pm 10$ & $165 \pm 7 * *$ \\
\hline Ppa mmHg & $15.3 \pm 0.7$ & $19.1 \pm 1.4^{* *}$ & $17.3 \pm 0.7$ & $25.3 \pm 1.2 * * \# \#$ \\
\hline PVR $\mathrm{mmHg} \cdot \mathrm{ml}^{-1} \cdot \mathrm{min}$ & $0.157 \pm 0.013$ & $0.213 \pm 0.021 * *$ & $0.157 \pm 0.015$ & $0.238 \pm 0.017 * *$ \\
\hline Psa $\mathrm{mmHg}$ & $117 \pm 5$ & $105 \pm 4 * *$ & $115 \pm 2$ & $108 \pm 2 *$ \\
\hline $\mathrm{SVR} \mathrm{mmHg} \cdot \mathrm{ml}^{-1} \cdot \mathrm{min}$ & $1.60 \pm 0.14$ & $1.44 \pm 0.08$ & $1.32 \pm 0.12$ & $1.18 \pm 0.05$ \\
\hline $\mathrm{SaO}_{2} \%$ & $92 \pm 0.4$ & $60 \pm 1.9 * *$ & $92 \pm 0.3$ & $51 \pm 1.6 * * \# \#$ \\
\hline $\mathrm{S} \overline{\mathrm{v}} \mathrm{O}_{2} \%$ & $54 \pm 1.9$ & $27 \pm 0.6^{* *}$ & $55 \pm 1.5$ & $23 \pm 0.6^{* * \# \#}$ \\
\hline$\dot{\mathrm{V}}_{\mathrm{O}_{2}} \mathrm{ml} \cdot \mathrm{min}^{-1} \cdot \mathrm{kg}^{-1}$ & $18.7 \pm 0.7$ & $16.0 \pm 0.4 * *$ & $20.6 \pm 0.7$ & $16.4 \pm 0.3 * *$ \\
\hline $\mathrm{CI}^{2} \mathrm{ml} \cdot \mathrm{min}^{-1} \cdot \mathrm{kg}^{-1}$ & $287 \pm 11$ & $276 \pm 6$ & $351 \pm 47$ & $341 \pm 20^{\#}$ \\
\hline $\mathrm{pHa}$ & $7.44 \pm 0.01$ & $7.55 \pm 0.01 * *$ & $7.44 \pm 0.01$ & $7.55 \pm 0.02 * *$ \\
\hline $\mathrm{PaO}_{2} \mathrm{kPa}$ & $12.9 \pm 0.2$ & $4.8 \pm 0.1 * *$ & $12.2 \pm 0.3$ & $4.5 \pm 0.1 * *$ \\
\hline $\mathrm{PaCO}_{2} \mathrm{kPa}$ & $4.2 \pm 0.0$ & $2.6 \pm 0.0 * *$ & $4.3 \pm 0.0$ & $2.8 \pm 0.0 * *$ \\
\hline
\end{tabular}

Data are presented as mean \pm SEM. HR: heart rate; RR: respiratory rate; Ppa: pulmonary artery pressure; PVR: pulmonary vascular resistance; Psa: systemic arterial pressure; SVR: total systemic vascular resistance; $\mathrm{SaO}_{2}$ : arterial oxygen saturation; $\mathrm{S}_{\overline{\mathrm{v}}} \mathrm{O}_{2}$ : mixed venous oxygen saturation; $\dot{\mathrm{V}}_{\mathrm{O}_{2}}$ : oxygen consumption; $\mathrm{CI}$ : cardiac index; pHa: $\mathrm{pH}$ of arterial blood; $\mathrm{PaO}_{2}$ : arterial oxygen tension; $\mathrm{PaCO}_{2}$ : arterial carbon dioxide tension; Group-C: salinetreated group; Group-EL: elastase-treated group. *: $\mathrm{p}<0.05$; **: $\mathrm{p}<0.01 \mathrm{vs}$ normoxia in each group; \#: $\mathrm{p}<0.05$; \#\#: $\mathrm{p}<0.01$ vs Group-C. 

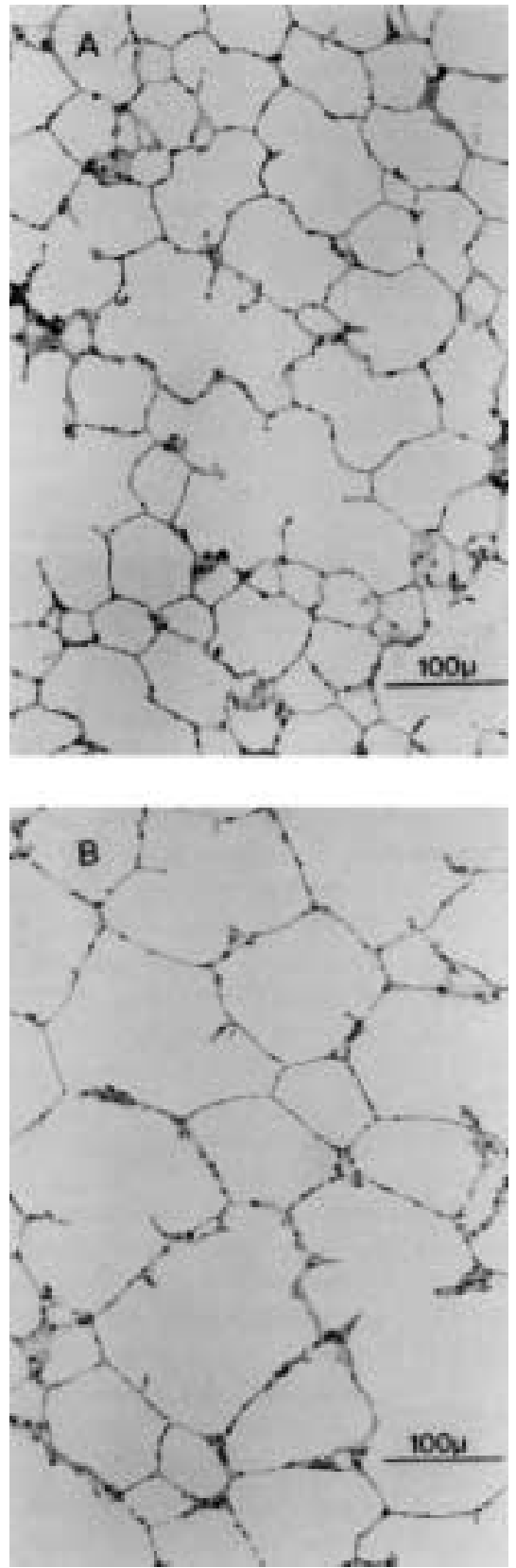

Fig. 1. - Lung histology. Shown is a slice from one rat of each group. A) Group-C; intratracheally instilled with saline 4 weeks before sacrifice. B) Group-EL; instilled with porcine pancreatic elastase. (Original magnification $\times 200$ ).

Table 3. - Percentage medial thickness of pulmonary arteries

\begin{tabular}{|c|c|c|}
\hline $\begin{array}{l}\text { ED } \\
\mu \mathrm{m}\end{array}$ & $\begin{array}{c}\text { Group-C } \\
\%\end{array}$ & $\begin{array}{c}\text { Group-EL } \\
\%\end{array}$ \\
\hline$<50$ & $4.4 \pm 0.3$ (4) & $7.8 \pm 0.9(5)^{\#}$ \\
\hline 50-100 & $3.3 \pm 0.7(6)$ & $7.2 \pm 0.5(10)^{\# \#}$ \\
\hline$>100$ & $2.0 \pm 0.6$ & $6.4 \pm 1.0(5)^{\# \#}$ \\
\hline
\end{tabular}

Data are presented as mean \pm SEM. Numbers in the parentheses are the number of the sections of arteries on which morphometry was made. Group-C: saline-treated group; Group-EL: elastase-treated group; ED: external diameter; \#: $\mathrm{p}<0.05$; \#: $\mathrm{p}<0.01$ vs Group-C. a)

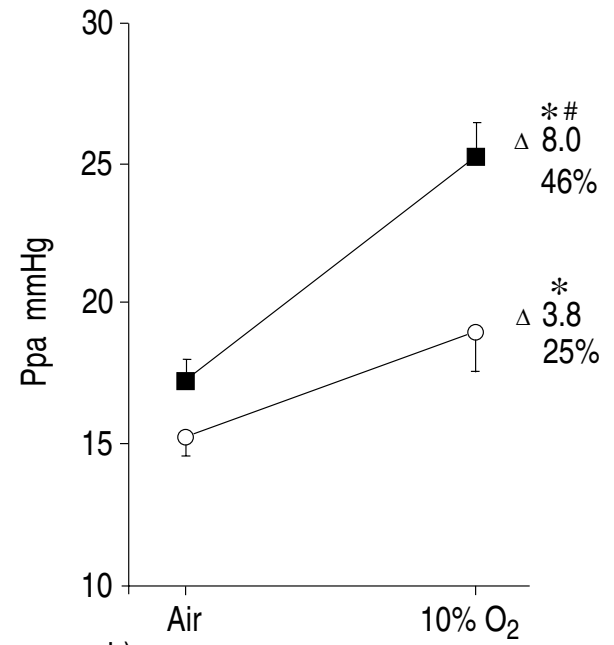

b)

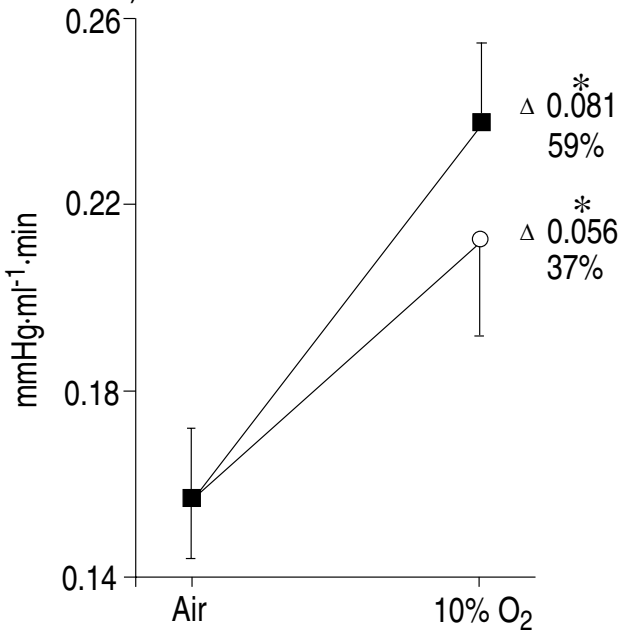

Fig. 2. - a) Response of Ppa to acute hypoxia. Sizes of the response are expressed on the right side as an absolute and as a percentage rise above the baseline. Acute hypoxic exposure significantly raised Ppa in both groups $(*: \mathrm{p}<0.01)$. The absolute and the percentage increase of Ppa by acute hypoxia was significantly larger in Group-EL than in Group-C (\#: $\mathrm{p}<0.05)$. b) Response of PVR to acute hypoxia. Magnitude of the response is expressed on the right side as in a). The response of PVR to acute hypoxia tended to be larger in Group-EL, but not of statistical significance. *: $\mathrm{p}<0.01$ vs air breathing. $\mathrm{O}$ : group-C $(\mathrm{n}=12)$; $\quad$ : group-EL $(\mathrm{n}=9)$. Ppa: pulmonary artery pressure; PVR: pulmonary vascular resistance; Group-EL: instilled with porcine pancreatic elastase; Group-C: instilled with saline.

both groups, although the change was not statistically significant. Ten percent $\mathrm{O}_{2}$ breathing did not cause significant alterations in cardiac index, despite consistent falls in $\dot{\mathrm{V}}_{2}$. Ppa of Group-C increased above baseline by $25 \%$ after breathing $10 \% \mathrm{O}_{2}(\mathrm{p}<0.01)($ fig. 2$)$. The rise in PVR in this group was $37 \%$ above baseline (fig. $2)(\mathrm{p}<0.01)$. The increase of Ppa in Group-EL after breathing $10 \% \quad \mathrm{O}_{2}$ was $46 \%$ above baseline, significantly higher than that for Group-C $(\mathrm{p}<0.05)$. Although the change of PVR in Group-EL tended to be larger than in Group-C, ANOVA did not reveal statistical difference between the two groups. However, right ventricular hypertrophy, as expressed by $\mathrm{RV} /(\mathrm{LV}+\mathrm{S})$, occurred in Group-EL (table 1). 
Table 4. - Body weight and pulmonary and systemic arterial pressure 3 weeks after elastase instillation

\begin{tabular}{lccc}
\hline & $\begin{array}{c}\mathrm{BW} \\
\mathrm{g}\end{array}$ & $\begin{array}{c}\mathrm{Ppa} \\
\mathrm{mmHg}\end{array}$ & $\begin{array}{c}\text { Psa } \\
\mathrm{mmHg}\end{array}$ \\
\hline $\begin{array}{l}\text { Group-C } \\
(\mathrm{n}=10)\end{array}$ & $249 \pm 4$ & $17.9 \pm 0.4$ & $120 \pm 2$ \\
$\begin{array}{l}\text { Group-EL } \\
(\mathrm{n}=15)\end{array}$ & $245 \pm 3$ & $20.8 \pm 0.4^{\# \#}$ & $119 \pm 1$ \\
\hline
\end{tabular}

Data are presented as mean \pm SEM. BW: body weight; Ppa: pulmonary artery pressure; Psa: systemic artery pressure; Group-C: saline-treated group; Group-EL: elastase-treated group; \#\#: $\mathrm{p}<0.01$ vs Group-C.

\section{Ppa 3 weeks after elastase instillation}

During air breathing Ppa of Group-EL was significantly higher than that of Group-C at this period of experiment $(\mathrm{p}<0.01)$ (table 4).

\section{Discussion}

This is the first description of the pulmonary haemodynamics of an emphysema model produced by intratracheal elastase. The study demonstrated that four weeks after tracheal instillation of pancreatic elastase, the change in pulmonary artery pressure when animals were exposed to $10 \% \mathrm{O}_{2}$ was significantly larger in the emphysema group than in the control group, and at this period the right ventricle was significantly more hypertrophic in the emphysema group.

In the calculation of PVR, we used the same Pcw, $3.8 \mathrm{mmHg}$, for both groups. This value is quite close to the left ventricular end-diastolic pressure of rats, 3.4 $\mathrm{mmHg}$, used by FRIED et al. [15]. Whilst it is possible that Pcw while breathing $10 \% \mathrm{O}_{2}$ was lowered by reduction of the blood returning to left atrium because of raised pulmonary vascular resistance [18], we assumed that the reduction of the left atrial pressure was negligible.

Different investigators have used widely varying amounts of porcine pancreatic elastase, ranging from 1.3-100 $\mathrm{U} \cdot 100 \mathrm{~g}^{-1} \mathrm{BW}$ in different animal species [1, 19-22]. In earlier work, we tested dose dependency of lung pressure-volume curve and morphometry using porcine pancreatic elastase ranging from $20-100 \mathrm{U} \cdot 100 \mathrm{~g}^{-1} \mathrm{BW}$ in rats [10]. The pressure-volume curve at $100 \mathrm{U}$ was more to the right and downward than at $80 \mathrm{U}$ and, in addition, animal mortality shortly after instillation was higher. Mean linear intercepts of animals treated with $100 \mathrm{U}$ were only slightly larger than those of animals with 80 U. From these results, we concluded that $80 \mathrm{U} \cdot 100 \mathrm{~g}^{-1}$ BW is optimal for a rat emphysema model produced by a single intratracheal instillation of porcine pancreatic elastase. With $80 \mathrm{U}$, mean linear intercept was $98 \mu \mathrm{m}$, 1.4 times that of the control value, $72 \mu \mathrm{m}[10]$. This degree of widening of alveolar space corresponds to human emphysema ranging from mild to relatively severe [23]. In the emphysema model produced by elastase instillation, mean linear intercept increases between 3-6 weeks, with no other significant change, although some functional parameters continue to change over 52 weeks [24].
While breathing air, the control animals showed mean systemic artery pressure, mean pulmonary artery pressure, cardiac index, and pulmonary resistance similar to previous results obtained for awake rats $[13,15,16$, 25]. Heart rate $[15,25]$ and respiratory rate [26] were also similar to other reports. Mean pulmonary artery pressure of the emphysema group after 4 weeks was higher than the values of the control group, but not statistically significant. However, mean pulmonary artery pressure three weeks after instillation of elastase, was significantly higher than that of the control group during air breathing (table 4). Right ventricular hypertrophy of the emphysema model was significant, even four weeks after instillation (table 1), suggesting the existence of an experimental period of pulmonary hypertension. It seems that, in this model, pulmonary hypertension recovers earlier than medial wall thickness and right ventricular hypertrophy.

It is presently accepted that total pulmonary vascular resistance is determined by two portions of the pulmonary bed, namely, the alveolar and the extra-alveolar segments [7, 8]. To the extra-alveolar vessels within the lung parenchyma, outward radial stress is applied by the surrounding tissue, and this resists the narrowing of vascular beds. Outward force exerted on vasculature by the lung tissue during resting respiration should be weaker in Group-EL than in Group-C. Attenuation of the opposite radial force exerted on pulmonary vessels against the hypoxic pulmonary vasoconstriction is probably one of the reasons why change in pulmonary artery pressure with $10 \% \mathrm{O}_{2}$ was higher in Group-EL.

Medial walls were significantly more thickened in Group-EL. An increased medial thickness produces a vascular hyperreactivity, which does not necessitate the concomitant presence of a changed smooth muscle sensitivity-reactivity. Increase in wall/lumen ratio reduces their structurally determined lumen and tends to potentiate the luminal reductions for a given smooth muscle reduction [27]. Then, an increase in pulmonary arterial wall thickness can also explain the enhancement of hypoxic pulmonary vasoconstriction.

The third possible reason for enhanced pulmonary vascular reaction to hypoxia is an increased responsiveness of the pulmonary vascular smooth muscle. The emphysematous lung produced by an endotracheal elastase instillation showed greater contractility to $\mathrm{KCl}$ in vitro, in a study in which lung parenchyma included vascular smooth muscle [5].

In summary, we reported on the pulmonary haemodynamics of an emphysema model produced by a single endotracheal instillation of elastase, $80 \mathrm{U} \cdot 100 \mathrm{~g}^{-1} \mathrm{BW}$. With this dose and four weeks after instillation, the right ventricle was significantly more hypertrophic in treated animals than in untreated animals. The medial thickness of small pulmonary arteries of the group treated with elastase was significantly increased. Pulmonary artery pressure responded significantly more to acute hypoxia in elastase-treated animals, although the vascular reactivity was not significantly different between the groups when the pressure response was evaluated as pulmonary vascular resistance. 


\section{References}

1. Hayes JA, Korthy A, Snider GL. The pathology of elastase-induced panacinar emphysema in hamsters. $J$ Pathol 1975; 117: 1-14.

2. Kaplan PD, Kuhn C, Pierce JA. The induction of emphysema with elastase. I. The evolution of the lesion and the influence of serum. J Lab Clin Med 1973; 82: 349-356.

3. Snider GL, Sherter CB, Koo KW, Karlinsky JB, Hayes JA, Franzblau C. Respiratory mechanics in hamsters following treatment with endotracheal elastase or collagenase. J Appl Physiol 1977; 42: 206-215.

4. Schraufnagel DE, Schmid A. Capillary structure in elastase-induced emphysema. Am J Pathol 1988; 130: 126-135.

5. Qian Su-Yue, Mitzner, W. In vivo and in vitro lung reactivity in elastase-induced emphysema in hamsters. Am Rev Respir Dis 1989; 140: 1549-1555.

6. Kapanci Y, Assimacopoulos A, Irle C, Zwahlen A, Gabbiani G. "Contractile interstitial cells" in pulmonary alveolar septa: A possible regulator of ventilation/ perfusion ratio? J Cell Biol 1974; 60: 375-392.

7. Howell JBL, Permutt S, Proctor DF, Riley RL. Effect of inflation of the lung on different parts of pulmonary vascular bed. J Appl Physiol 1961; 16: 71-76.

8. Lopez-Munitz R, Stephens NL, Bromberger-Barnea B, Permutt S, Riley RL. Critical closure of pulmonary vessels analyzed in terms of Starling resistor model. $J$ Appl Physiol 1968; 24: 625-635.

9. Wetzel RC, Martin LD. Pentobarbital attenuates pulmonary vasoconstriction in isolated sheep lungs. Am J Physiol 1989; 257: H898-H903.

10. Sato S, Kato S, Takahashi H, Arisaka Y, Takahash $\mathrm{K}$. Dose dependency of intratracheal elastase-induced changes in pressure-volume curve and morphometry in rat lungs. Tohoku J Exp Med 1990; 161: 101-110.

11. Hayatdavoudi G, Crapo JD, Miller FJ, O'Neil J. Factors determining degree of inflation in intratracheally fixed rat lungs. J Appl Physiol: Respirat Environ Exercise Physiol 1980; 48: 389-393.

12. Michel RP. Arteries and veins of the normal dog lung: qualitative and quantitative structural differences. $A m J$ Anat 1982; 164: 227-241.

13. Rabinovitch M, Gamble W, Nadas AS, Miettinen OS, Reid L. The rat pulmonary circulation after chronic hypoxia. Hemodynamic and structural features. $A m J$ Physiol 1979; 236: H818-H827.
14. Weeks JR, Jones JA. Routine direct measurement of arterial pressure in unanesthetized rats. Proc Soc Exp Bio Med 1960; 104: 646-648.

15. Fried R, Meyrick B, Rabinovitch M, Reid L. Polycythemia and the acute hypoxic response in awake rats following chronic hypoxia. J Appl Physiol: Respirat Environ Exercise Physiol 1983; 55: 1167-1172.

16. Meyrick B, Gamble W, Reid L. Development of clotalaria pulmonary hypertension: hemodynamic and structural study. Am J Physiol 1980; 239: H692-H702.

17. Fulton RM, Hutchinson EC, Jones AM. Ventricular weight in cardiac hypertrophy. $B r$ Heart $J$ 1952; 14 : 413-420.

18. Belenkie I, Dani R, Smith ER, Tyberg JV. Ventricular interaction during experimental acute pulmonary embolism. Circulation 1988; 78: 761-768.

19. Bellofiore S, Eidelman DH, Macklem PT, Martin JG. Effects of elastase-induced emphysema on airway responsiveness to methacholine in rats. J Appl Physiol 1989; 66: 606-612.

20. Fonzi L, Lungarella G. Correlation between biochemical and morphological repair in rabbit lungs after elastase injury. Lung 1980; 158: 165-171.

21. Harkema JR, Mauderly JL, Gregory RE, Pickell JA. A comparison of starvation and elastase models of emphysema in the rat. Am Rev Respir Dis 1984; 129: 584591.

22. Kimmel EC, Winsett DW, Diamond L. Augmentation of elastase-induced emphysema by cigarette smoke. Am Rev Respir Dis 1985; 132: 885-893.

23. Thurlbeck WM. Internal surface area and other measurements in emphysema. Thorax 1967; 22: 483-496.

24. Snider GL, Sherter CB. A one-year study of the evolution of elastase-induced emphysema in hamsters. $J$ Appl Physiol: Respirat Environ Exercise Physiol 1977; 43: 721-729.

25. McMurtry IF, Morris KG. Platelet-activating factor causes pulmonary vasodilation in the rats. Am Rev Respir Dis 1986; 134: 757-762.

26. Olson EB, Dempsey JA. Rat as a model for humanlike ventilatory adaptation to chronic hypoxia. J Appl Physiol: Respirat Environ Exercise Physiol 1978; 44: 763-769.

27. Folkow BUG, Hallback MIL. Physiopathology of spontaneous hypertension in rats. In: Genest J, Koiw E, Kuchel O, eds. Hypertension. New York, McGrawHill Inc., 1977; pp 507-529. 